\title{
The development of community based adult mental health services - a research contribution
}

\author{
JACKIE POWELL, Lecturer in Social Work Studies; and ROBIN LOVELOCK, Fellow in \\ Applied Social Studies, Department of Social Work Studies, University of \\ Southampton, Southampton SO9 5NH
}

The desire to provide care and services for people with mental health problems in a community context, rather than in large institutions, is a longestablished feature of Government policy. In the more local context of the Portsmouth and South East Hampshire District Health Authority, a strategy of decentralising both the organisation and the delivery of services for adults with mental health problems began to be implemented early in 1986. Five multidisciplinary area community mental health teams would work with and alongside other serviceproviders in their localities to provide a range of support, including residential, day and other community and domiciliary services.

The City of Portsmouth itself was to be divided into three areas, namely Cosham, Central Portsmouth, and Southsea. Staff members of the corresponding three teams would initially be based on the St James' Hospital site in Portsmouth, while colleagues serving the two areas of the so-called 'County' part of the Health District, lying to the north-east, would be based at Havant Day Hospital, ten miles or so from St James'. The principles underlying this decentralisation strategy emphasised recognising clients as individuals and providing flexible local services appropriate to their needs, in as normal a setting as possible.

This paper, based on our recently published Interim Report (Powell \& Lovelock, 1989), summarises research carried out during the first year of a two-year study, funded from District Joint Finance, of Portsmouth's adult mental health services in transition. Much of the data presented in the Interim Report and in this paper is a baseline with which to compare a pattern of services yet to emerge fully. Nevertheless, certain key issues can be highlighted as being of pressing current concern and of relevance to a wider audience.

As elsewhere, two strands are interwoven in the changes taking place in Portsmouth's mental health services. The eventual closure of St James' Hospital is an element in the District's plans, with the 'winding down' of hospital-based provision proceeding handin-hand with the building up of more acceptable and accessible community based services. The aims and principles of the new-style service clearly imply a concern to offer both long and short term forms of help, and to provide both residential and community facilities. The balance of attention in our study is upon the development of the community oriented service, with the run-down of the hospital given much less direct prominence.

In addition to outlining some of our early findings, this paper advocates and exemplifies a style of research which can assist the ongoing process of service development. Our Interim Report was conceived as a working document and has already been used as a vehicle for formal feedback within the Health District. We see it as offering service managers, planners and practitioners in the District Health Authority and beyond an opportunity to reflect upon and to clarify a number of issues. In the context of rapid and significant change it is surely important that all those involved in providing the new-style service should take time for constructive reflection upon where they as professionals are going, in the light of a systematic review of changes so far.

\section{The study}

Our research began in January 1988. Its focus is the work of one multidisciplinary team developing a local service, over the time-span of its move from a base in the grounds of St James' Hospital to purposebuilt accommodation in the Cosham area which it serves. The evaluation is essentially concerned with the implementation of the decentralisation strategy, not with its impact in terms of individual clinical outcomes. Our broad aim is to describe fully the operation of the new service as it moves away from the hospital into its community base, and to assess its impact upon its various users and its immediate providers.

Our approach to service evaluation takes particular account of two key features evident in the development of community based approaches in many fields. It pays attention to the different interests and perspectives of the several parties or 'stakeholders' involved in any caring intervention; it also acknowledges that particularly where a service is new or selfconsciously evolving, its organisation and content 
are themselves necessarily in the process of being worked out and specified.

The main findings presented are concerned with the background history of the new-style mental health service in Portsmouth and, in greater detail, with the continuing development of the Cosham service during the first nine months of 1988 , which we have called the 'pre-move phase'. Information being collected to assess the extent of collaboration with other agencies, in particular the local Social Services Centre, has not been included, while the important perspectives of various categories of service user will be studied by way of interviews during the second year of the study. We attempt to highlight important issues arising in the process of decentralisation and conclude with some brief comments on the value of learning from experience.

\section{Background and early development of the service}

\section{The pace of change}

Given the importance of history to the process of change, a natural starting point was the background and early stages of the transition of Portsmouth's adult mental health services into the community. Following the publication of the District Health Authority's Strategic Review in November 1983, the Unit Management Team took the opportunity to produce a written response, formalising many of their own and colleagues' current thoughts about redefining the Unit's philosophy and approach to the care of people with mental health problems. The overall strategy set out in their document entailed the systematic development of a whole new community service throughout the catchment area, along with the simultaneous run-down of institutional services based on the St James' Hospital site. While some service developments were already well-established in the community, the proposals emphasised the decentralisation of the organisation, as well as the delivery, of the service.

This fundamental rethinking, and the subsequent preparatory reorganisation for 'going local', took place over a relatively short period of time when the new, 'Griffiths-style' management structure was also being rapidly introduced into the National Health Service as a whole, bringing additional dimensions of radical change.

\section{City-wide issues}

In the early stages of implementation, the overall District Strategy has, as expected, taken a slightly different path in each of the three areas making up the City. However, it was also evident from the outset that in establishing a community based service, similar issues would have to be addressed in each area. Each team would be contributing a general philosophy into a particular locally based service, aiming to be widely accessible and to meet a broad range of needs, including those of people with longer term mental health problems. The development of a community team as the focus for both the organisation and delivery of services would also make consideration of the role of the residential unit within the overall service an important priority.

A major influence on the early development of the Cosham service has been the need to develop an integrated service, bringing together community and residential elements. There are a number of reasons for this, essentially bound up with the fact that Cosham's residential facility, Vinten House, situated away from the main buildings, but still in the grounds of St James' Hospital, is one whose philosophy and practice challenge traditional ideas about in-patient care and embrace a community role for its staff. In addition, the Cosham team was the first within the Unit to have an administrative base away from the main hospital buildings - although again still on the site. The central reason for the decision that our evaluation should focus on the Cosham service was that both residential and community aspects would leave the main site together in due course. With each element having its own base away from the main buildings from early on, the integration of two overlapping but separate parts of the total service has been a dominant theme.

In its attempts to develop greater accessibility, the Cosham team has responded in broadly similar ways to the other teams in the city, introducing an open referral system and attempting to foster links with other local agencies and organisations, particularly in early attempts to develop a better service for people with continuing care needs. Unlike the team in Southsea, an area where a substantial number of people with longer term mental health problems have been identified, Cosham staff have not created a designated team of people for this work, although certain individual team members have taken on and maintained 'long term clients' as one aspect of their overall workload.

\section{Day-to-day operation of the Cosham service}

\section{The logging exercise}

In order to describe systematically how the overall service was operating in the 'pre-move' phase, and in particular to examine how its various parts related and intermeshed, a logging study was set up. This involved all front-line service providers recording their activities during three separate weeks approximately one month apart. The data produced have 
been analysed and presented in two ways: from the perspective of where staff spent their time, and in terms of their day-to-day activities.

\section{Influence of location and work pattern}

One of the key points to emerge was that while the Cosham team as a whole had a shared organisational and administrative base during the 'pre-move' period, namely North Lodge, the residential unit, Vinten House, was to a lesser extent also an organisational base for those team members mainly working there. By virtue of its being a residential facility, Vinten staff did much of their direct client-related work in the House too.

To look in more detail at staff's work activities, we found it necessary to acknowledge the 24 hour daily duty cycle at Vinten House as a fundamental structure, around which additional staff activities, and especially client-related work in the local community, become possible. The pattern of activities of staff based at North Lodge fell more or less neatly into 'a typical week', although an important day-by-day administrative structure pertained for them. They went out from and returned to North Lodge, and almost all of their direct client contact took place in people's own homes and/or in community and health centres in the Cosham area.

\section{Areas of overlap and diversity}

The physical separation between North Lodge and Vinten House, at different points on the perimeter of the hospital site, and the different duty patterns of staff, were certainly important factors. However, there were also significant areas of overlap and shared activities between the staff groups.

Our analysis of the data with respect to where staff spent their time revealed that much of the overall service was being provided in the local community in a range of locations. This was in fact how and where the overlapping roles of staff based respectively at North Lodge and at Vinten House came together to provide a multi-faceted and broadly community focused service. While Vinten House staff on the whole spent less of their time working away from their home base than did their North Lodge colleagues, they used a similar range of community locations. There was substantial variation between individual team members in their use of such venues, reflecting personal preference and style of working as much as professional differences.

Overall, the data present a diverse picture of activities within the overall developing service. While this does not necessarily indicate that the service is as yet a comprehensive one, it does suggest that it is already broadly based. The physical separation of its two bases has done little to encourage increased contact among the team as a whole, although following the introduction of a weekly team meeting there was evidence of increased time spent together. However, the 'non-traditional' community role of those staff based at Vinten House was clearly demonstrated, highlighting an important area of overlap between residential and community provision within the overall service. These findings raise a number of issues concerning the role of an acute residential resource within a comprehensive locally based service; questions which were reflected in the main preoccupations of the Cosham team during the late spring and summer of 1988 , as they planned for the move of the total service into a shared community base.

In the event, the staff hitherto based at North Lodge duly moved to their new purpose-built community base in Cosham, Acorn Lodge, at the end of October 1988. They left 'Vinten'-i.e. the rest of the staff team and the residential unit as such - on the main hospital site, some four and a half miles away. The possibility of a 'split move' occurring had been 'on the agenda' throughout the summer months, with the discussion largely centring around the issue of medical cover for the community based acute residential facility.

This matter is not simply relevant to the Cosham service, although it was seen as such in some quarters. It raises broader questions about the still problematic relationships between the new-style general managers, appointed following the implementation of the 1983 Griffiths Report on the NHS, and the consultants. It also relates to the changing role of psychiatrists in the context of community mental health teams, and their particular contribution to the treatment of people with mental health problems. These issues are of increasing concern in the planned process of establishing community based services (McKee, 1988) and, we suggest, need to be addressed as a matter of some immediacy, both in Portsmouth and elsewhere.

\section{The referral process}

\section{Analysis of new referrals}

Having examined the nature of the service during the pre-move period, it was important to identify the main users of the service and to explore the referral process operating during the first phase of our research. A sample of new referrals during a six-month period prior to the move into the community was studied, using data drawn from 'the referral book' maintained by the team's administrative staff and from the clients' case files. It is important to note that this information does not represent a full picture of team members' workload, even in terms of direct client-related activities. Direct in-patient admissions are excluded, as, by definition, is ongoing work with 
'continuing care' clients. Some of the people included in our sample may of course later receive long term help, just as they may also have (or already have had) a period of in-patient care.

\section{Direct users of the service}

The pattern of new referrals was relatively stable at some 25 to 30 per month, with twice as many men as women and two-thirds of the people concerned not previously known to the service. GPs were overwhelmingly the main source of these referrals; their referral letters gave little evidence of clients themselves actively seeking help from the service on their own initiative.

While it is notoriously hard to categorise adequately reasons for referral (Phillips et al, 1988), a content analysis of the statements made by GPs in their referral letters revealed anxiety and/or depression predominating as identified forms of distress for which specialist help was sought on these clients' behalf. Background difficulties in the areas of relationships and life events were noted as significant contributors to these conditions.

\section{Team response}

In the vast majority of cases, where urgent response was not required, an initial team discussion took place within a week of a referral being received. One team member was then identified as the person to seek direct contact with the client to further assess and negotiate the most appropriate and acceptable form of help. Over the period studied so far, the initial response to referrals, whether prior to or following team discussion, has been shared increasingly among all members of the team. Thus an open referral system to the team is in operation, rather than direct referral from the GP to the consultant for an initial medical assessment. In addition, the staff of the in-patient unit serving the Cosham area have increasingly become involved in working with newly referred clients in the community, in addition to their residential commitments.

\section{Negotiating boundaries and setting priorities}

These findings raise questions about how the service is perceived and used by its main group of referrers, namely GPs. The nature of the majority of referrals gives some indication as to GPs' expectations regarding a locally based community mental health service. While external agencies can significantly influence the nature of work undertaken by the mental health service, priorities can be set and substantially determined by the service itself, albeit in negotiation with other agencies.

High priority is given in the Portsmouth Health District to ensuring an adequate service for clients with longer term mental health problems. Thus maintaining a balance between new referrals, predominantly from GPs seeking help for people with anxiety and/or depression, and ongoing work with continuing care clients, has become an increasingly pressing issue. Questions about setting priorities and managing workload are basic to the organisation of the community team, and therefore central, not peripheral, to their existence (Øvretveit, 1986). Without underestimating the substantial amount of work already undertaken, the Cosham service needs to look more closely at how decisions are made about limiting or extending individual and team workloads and about setting and changing priorities. As Øvretveit, Temple \& Coleman (1988) suggest, this responsibility rests with both senior management, in the setting of initial boundaries and objectives and defining basic aspects of organisation, and with the team itself, in defining arrangements for managing its agreed workload. Achievements in these areas are vital for successful teamwork and thence to improving the overall service to its various users.

\section{Concluding remarks}

The first year of our study, during which we have examined the development of one local community mental health team in the period before it physically left the main hospital site, has indicated a number of issues and concerns which focus around two of the key planks of Portsmouth DHA's development strategy for adult mental health services: the integration of residential and community facilities to provide a comprehensive service in and for particular localities, and multidisciplinary teams as a basis of service organisation, delivery and development. Both the organisation and the priorities of the service are in the process of changing; the detail of this and the issues emerging have been touched upon throughout this paper, as in our Interim Report (Powell \& Lovelock, 1989). In the latter document we have suggested that further careful attention be given to:

(a) a number of dimensions of the role of a community based acute residential facility, and

(b) aspects of team organisation, in particular concerning workload management and priority setting in a devolved service.

As was indicated at the beginning of this paper, our Interim Report has been conceived as a working document, and in a sense forms part of the research process; it provided an opportunity to report on work in progress and to offer a reflective account of the continuous process of moving out and its impact on some of the various interested parties. Two halfday workshops have been held to present and consider the content and implications of the report. One was essentially aimed at sharing progress with the immediate service providers and their managers; the 
other was an attempt to communicate developments so far with a District-wide audience convened by the Unit General Manager, including some Social Services personnel.

The seminar involving a wider audience began with a brief presentation of the main findings of the Interim Report by the authors. This was followed by some observations from the Cosham team on 'the experience of being researched' during this period of transition. There was general agreement that having an 'independent view' was helpful in encouraging an atmosphere of questioning and reflection, enabling them to see more clearly some of the issues underlying their day-to-day activities.

The second half of the programme was more specifically structured to facilitate both informationsharing and learning across local area and professional boundaries. Small groups, deliberately including managers and practitioners from different disciplines and areas, were invited to discuss the two key issues identified above, to which we added the question of how to provide for ongoing systematic review. This was followed by a plenary discussion, during which the main points from each group were shared and brought together.

Becoming more actively and directly involved in the dissemination process, and in encouraging participants to identify general learning points from the particular experience of one local service, is a relatively new experience for us as researchers. We would, however, argue the need for such initiatives in the context of researching organisational change. Planning for change inevitably involves uncertainty:

Planning should be a continuous process of generating and testing ideas, with review and feedback mechanisms built into the system as key features (Kingsley \& Towell, 1988, p. 67).

There are many ways in which the experience of service development can be used as learning for subsequent initiatives. In this paper we have tried to exemplify an approach to evaluation which can directly contribute to the ongoing process of service development, in this case assisting a service actively engaged in establishing comprehensive and locally based mental health facilities.

\section{References}

KIngsley, S. \& Towell, D. (1988) Planning for high quality local services. In Community Care in Practice: Services for the Continuing Care Client. (eds A Lavender and F. Holloway). Chichester: Wiley, pp. 51-74.

MCKEE, L. (1988) Conflicts and context in managing the closure of a large psychiatric hospital. Bulletin of the Royal College of Psychiatrists, 12, 310-319.

ØVRETVEIT, J. (1986) Organisation of Multidisciplinary Community Teams. Uxbridge: BIOSS, Brunel University. -, Temple, H. \& Coleman, R. (1988) The Organisation - and Management of Community Mental Health Teams. London/Guildford: Good Practices in Mental Health/ Interdisciplinary Association of Mental Health Workers.

Phillips, D., BARRIT, A., BOOTH, T., JoNEs, D. et al (1988) Classifying psychiatric crises: problems of reliability in post-coding open-ended questions. Research, Policy and Planning, 6, 1-6.

Powell, J. \& Lovelock, R. (1989) Cosham Mental Health Service Evaluation: Interim Report. Southampton, University of Southampton.

A full list of references is available on request from the authors.

\section{To all current and ex members of the Association of University Teachers of Psychiatry}

The Association receives each year over 100 sums of $£ 1$ or $£ 2$ as a result of standing orders which have never been cancelled. In the case of those members who are also paying the full subscription of $£ 10$ and remain on the membership list we can write to them advising them to cancel their additional subscription. However, in the case of the others we have no means of tracing their identities and reminding them to cancel the accounts. We therefore have to treat the sums involved as donations which we are unable to refund. I would ask all ex-members of the Association who are not paying the current $£ 10$ annual subscription on 1 July to contact their banks and either cancel their standing orders or increase them to $£ 10$ and send me a cheque for the balance of this year with sufficient details for me to fill out a new membership form, i.e. including departmental address and address for correspondence.

Alex Kellam

University Hospital of Wales Treasurer, AUTP 